doi: $10.15503 /$ jecs20182.93.106

\title{
THE IMPACT OF ANXIETY ON SPEAKING I ADOLESCENT AND ADULT GROUPS OF ENGLISH LEARNERS
}

\author{
BOGUSŁAWA GOSIEWSKA-TUREK \\ Institute of English, University of Opole, \\ Pl. Kopernika 11 Opole, Poland \\ E-mail address: boggosiewska@gmail.com
}

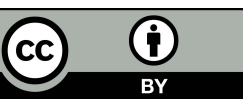

\section{ABSTRACT}

Aim: The aim of this article is to investigate the interdependence between adolescent and adult students' anxiety and their foreign language speaking achievements. It has been proved that there is no correlation between adolescent learners' anxiety and their speaking attainments in a foreign language as well as that there is a weak correlation between adult students' anxiety and their speaking achievements.

Method: The author of the study employed quantitative research. Data was collected from anxiety questionnaires completed by the students and from achievement sheets filled in by the English teacher based on five-minute speeches performed by adolescent and adult students.

Conclusion: According to the research results, there is no interdependence between adolescent students' anxiety and their speaking attainments and the correlation between adult students' anxiety and their speaking achievements is weak. Nevertheless, a number of other studies revealed the interdependence between students' anxiety and their speaking attainments. Therefore, limitations of the study should be born in mind, and the results of the following study can be applied only to the subjects participating in the study. Hence, it is relevant to repeat the study with larger samples of subjects.

Key words: foreign language, second language acquisition, affective factors, anxiety, speaking, adults, adolescents.

\section{BASIC ISSUES RELEVANT TO FOREIGN LANGUAGE ANXIETY}

Before anxiety is discussed it is vital to focus on Krashen's affective filter hypothesis (1987). According to his hypothesis, affective factors in language learning serve as a filter which drains language input. Krashen argued that individuals acquire the second language on condition that they are provided with comprehensible input. He also enumerated four factors which affect foreign language acquisition. These are: motivation, attitude, anxiety and self-confidence.

"Motivation has been defined in terms of two factors: on the one hand learners' communicative needs, and on the other, their attitude towards the second 
language community" Linghtbown \& Spada (2006, p. 63). Learners who study in order to improve their social or economical opportunities, that is to obtain a place at the university or to get a better job, are equipped in instrumental motivation. Some students possess integrative motivation. These are learners who study to learn about the culture and people related to the target language (Linghtbown, \& Spada, 2006).

Attitude is recognized in psychology as "the general and enduring evaluative perception of some person, object or issue" (Cacciopo, 1994, p. 261). Attitude is determined by the commitment. Students who demonstrate positive learning attitude are more willing to perform actively and achieve higher grades. Therefore, positive attitude is beneficial for second language learning, whereas negative attitude hinders students' motivation (Brown, 2001).

Self confidence is an affective factor which undoubtedly has an impact on students' foreign language performance. Lack of self-confidence is thought to be an obstacle in communication. Confident students dare to communicate, no matter how many mistakes they commit. They are also willing to participate in an oral communication on various topics in front of the whole classroom. Moreover, confident students improve their language proficiency through learning from mistakes.

Last but not least affective factor enumerated by Krashen (1987) is anxiety, which will be discussed more broadly. Anxiety is a notion experienced by all individuals. Adults may be affected by anxiety related to their job, whereas in adolescents anxiety is commonly caused by peer pressure. Second language students deal with anxiety concerning classroom activities such as taking a test or speaking in front of the whole classroom. According to Spielberger (1972, p. 19), anxiety is "an unpleasant emotional state or condition which can be characterized by subjective feeling or tension, apprehension and worry and by activation or arousal of the automatic nervous system that accompanies these feelings."

While all the aspects of anxiety appear to be of equal importance, it seems to be justified that some components require thoughtful analysis as they affect foreign language performance. These forms of apprehension can be distinguished as: general, social and trait anxieties (Spielberger, 1972).

General anxiety is a wide concept which underlines potential reaction to pain evolving stimuli (Piechurska-Kuciel, 2008). Along with general anxiety, manifest anxiety is used interchangeably. It is experienced in the form of physical tension, limited energy levels and depression symptoms. Both forms of anxiety can be recognized by higher heart rate, sweating, trembling, weakness as well as feeling of imminent danger and apprehension (Piechurska-Kuciel, 2008).

Consecutive form of anxiety is social anxiety. Briefly speaking, it is individuals' concern about unfavourable evaluation by others in new settings. Thus, people who experience high level of social anxiety may consider that their behaviour will be assessed negatively. Socially anxious individuals speak less than confident people. They are less likely to initiate communication and are prone to avoiding anxiety-provoking situations. 
General anxiety has been subdivided into state and trait anxiety. State anxiety expresses "subjective and conscious feeling of apprehension and tension accompanied by stimulation or activation of the autonomous nervous system" Spielberger (1966, p. 17). Trait anxiety, on the other hand, encompasses behavioural predisposition situated in the past experience. It is relatively stable and distinctive from the characteristics of anxiety appearing in response to stress (Novy, \& Nelson, 1995). Trait anxiety also reflects a number of settings in which people manifest state anxiety. Elevated level of trait anxiety coexists with a high level of state anxiety but high level of state anxiety does not have any correlation with elevated level of trait anxiety (Piechurska-Kuciel, 2008).

The researchers defined further categories of anxiety strictly related to the foreign language learning. Horowitz (1991) characterized principal causes of language anxiety as communication apprehension, test anxiety and the fear of negative evaluation. Communicative apprehension occurs when learners possess mature thoughts and ideas which they are not able to express as a result of their fear of getting into authentic communication. Communication anxiety can be distinct for some settings such as public speaking, and may be a component of general anxiety which arises in various contexts. McCroskey (1980, 1984 as cited in 1987) distinguished several causes resulting in students being quiet (these also can be applied to adult students). These are the following reasons: low intellectual skills, lack of acceptable speaking skills, social alienation, communication anxiety, limited self-esteem and also a social and ethnic component.

Furthermore, Daly (1991) explained that children who had early opportunities to talk are more likely to be less anxious. He also claims that students who participate in model social interactions are less apprehensive than those whose communication experiences are incomplete and inadequate. This description justifies that the level of communication apprehension in students originates in their social environment (Daly, 1991).

Communicative apprehension contributes to the language anxiety. Individuals who are anxious about speaking are more likely to be anxious when they speak a foreign language in a classroom context where in addition to feeling "less in control of the communicative situation, they also may feel that their attempts at oral work are constantly being monitored" (Horowitz, Horowitz, \& Cope 1986, p. 127).

The second type of language anxiety is test anxiety. Testing is particularly prominent measurement of students' achievements. It establishes situation when anxiety related emotions are noticeable from limited to decreased levels of anxiety. It also expands the feeling of uneasiness, apprehension, distress or depression in the situation when learners experience doubts related to their abilities or fear of being unprepared (Harleston, 1962).

Test anxiety is a "situation specific anxiety" (Zohar, 1989, p. 330). It forces students to behavioural responses which are usually debilitating. It describes permanent individual variations in anxiety levels in different evaluative settings. Number of aspects are related to test anxiety. These are low self-esteem, 
academic failure and passivity (Piechurska-Kuciel, 2008). Furthermore, gender is one of the most significant aspects, where females are more prone to be anxious (Gierl, \& Rogers, 1996). Test anxiety is also more likely to develop with age, when negative testing experience creates hostile reaction among students (Piechurska-Kuciel, 2008).

Fear of negative evaluation is another form of foreign language learning anxiety. It is not limited to a testing context, but it can also appear in any social and evaluative situation such as job interview, but also during speaking in a second language in a classroom.

The major distinction between test anxiety and fear of negative evaluation is the fact that fear of negative evaluation does not have to be correlated with testing context but may emerge in a number of other contexts. It is primarily associated with social anxiety and low self-esteem. Individuals with high selfesteem are perceived as more socially engaged and are more prone to be successful foreign language learners. They learn from their unfavourable assessment such as negative evaluation (Piechurska-Kuciel, 2008).

Consequently, learners who experience fear of negative evaluation have the tendency to display higher level of foreign language anxiety, primarily as a result of their negative self-perception of their own speaking abilities (Kitaro, 2001). More anxious learners may attempt to limit the probability of being evaluated negatively through passive interactions (Piechurska-Kuciel, 2008).

\section{ANXIETY IN ADOLESCENT AND ADULT LEARNERS}

Although anxiety belongs to fixed aspects of learning, it varies with age. Age is an essential factor affecting language anxiety in terms of the way of thinking, learning abilities and learning styles (Latif, 2015).

Adolescence is frequently called storm and stress period, which can be characterized by parent-adolescent conflict, emotional moodiness and risk taking behaviours (Hines, \& Paulson, 2006). Also, the strong need for independence and peer approval is essential in adolescents' development. Belonging to a specific group provides adolescents with a sense of existence, therefore friendship and emotional support are vital.

Adolescence and challenges posed by this period are the causes of anxiety symptoms. In adolescence, social incomprehension may result in social and evaluative concerns followed by performance anxiety. Also, elevated level of fear of criticism and failure has been noticed in adolescents (Piechurska-Kuciel, 2008).

According to Piechurska-Kuciel (2008), the emotional experience of anxiety in adolescents typically has two types of mechanisms: physical sensations and the feeling of fear and nervousness. High level of anxiety may have an impact on decision making, adolescents' thinking, perceptions of the environment, learning and concentration.

Adult learners are more autonomous than adolescents and more capable of developing their language skills and language experience (Latif, 2015). 
According to Krashen (1987), adult learner is a formal thinker who is capable of employing formal operations such as conscious grammar, meta-awareness, and general abstract rules learning. Nevertheless, they are affected by a higher level of anxiety than the younger learners. Thus, they frequently refrain from pronouncing, translating or writing words in the foreign language which they are not comfortable using (Latif, 2015).

Adults come to class equipped with history originating from their previous education, which can be both positive and negative (Latif, 2015). They also may be more critical of their own learning abilities than adolescent learners. Hence, the concern about various approaches towards adult learners is of great value.

Anxiety phenomenon is the area which can appear in all stages of foreign language acquisition and may affect accuracy and speed of learning (Kostyuk, Meghanathan, \& Isokpehi, 2010). Adult learners with their luggage from previous language learning may possess certain inhibitions which do not allow them to acquire a foreign language as efficiently as younger learners.

To conclude, adult and adolescent students are exceptionally sensitive to various anxieties both in the classroom context and outside the school while communicating in the foreign language. Thus, the teacher's role is to take into consideration their needs as learners appropriately to their age.

\section{PROBLEMS APPEARING DURING ORAL COMMUNICATION IN A FOREIGN LANGUAGE}

A proficient foreign language user possesses various skills such as the ability to read a paper or to write a letter in a foreign language. However, oral communication is the most commonly used method of communication in real life. Therefore, it is vital for the students to master this skill and learners should be provided with the basis of the oral practice, that is phonetics, grammar and contextual accuracy (Shastri, 2010).

Oral communication differs from reading and writing activities and provides more opportunities for disrupting students' self-esteem. In spoken communication learners are unable to consult dictionaries for vocabulary, grammar use and correct pronunciation. Also, insecure students experience fear of making mistakes or receiving negative feedback from the teacher. All these aspects result in problems with speaking activities faced by the learners.

One of the most essential problems is the situation where students refuse to talk in the foreign language. Some learners, primarily adults, may be critical of teaching methods or activities reflecting the teaching they experienced in their previous career as learners.

Sometimes, classroom activities can be boring or aimed at the wrong level. Also, some teachers use primarily their mother tongue in the classroom. If teachers, whose role is also to serve as a model, are not willing to speak the target language, they cannot expect from the learners to overcome their inhibi- 
tions while speaking. Also, some adolescent students remain silent as they fear of being assessed by their peers. In this case, it is the teacher's role to encourage them to participate in oral communication (Komorowska, 2005).

Another problem appearing during oral communication is low participation of the students. It has been noticed that some learners participate in the class actively, whereas others refrain from it. Students' learning style is the first factor which can hinder their participation. Harmer (2001) described learners as: coverages, conformists, concrete learners and communicative learners. Coverages are the students who prefer to work independently. Conformists choose to learn about the language, rather than using it. They perfectly accomplish teacher's instructions. Concrete learners enjoy using the language in communication in the classroom and communicative learners, who are risk takers, appreciate social interactions and communication outside the classroom.

Furthermore, students' language level contributes to their participation in the lesson. Generally, three levels of language proficiency can be recognized: beginner, intermediate and advanced. At the beginner level, students' progress is easily noticeable but at intermediate level progress is subtler, which can discourage them from participation (Harmer, 2001).

Discussing the reasons for students' refraining from participation in speaking activities, lack of general knowledge and students' cultural values can be also enumerated. To overcome these problems teachers should rely on students' prior knowledge and show the students how to disagree respectfully with the other students' ideas.

Moreover, it is very common for students to avoid communication in the target language in the classroom context. In a number of cases teachers choose activities which are improper for a certain group of students, e.g. a group of beginner students being asked to discuss political system in the UK. It means that the teacher selecting the task made the use of a native language inevitable.

All in all, problems faced by adolescent as well as adult foreign language learners are strictly related to their age. Adults bring to the classroom vast experience which can affect their willingness to communicate. Adolescents, on the other hand, are frequently confused about the world and experience lack of motivation which can affect their communication in the target language. Therefore, to overcome problems with speaking in a foreign language, teachers should promote the ideas to increase interaction among students.

\section{EMPIRICAL RESEARCH}

The main objective of the study was to investigate the impact of learners' anxiety on their speaking performance in a foreign language. To explain it in detail, the researcher examined anxiety of adult and adolescent learners and its impact on their attainment in speaking performance. Regarding the 
second objective, the study was also aimed at discovering whether anxiety had a positive or negative influence on their speaking performance in the foreign language. Therefore, the researcher formulated null hypotheses on the basis of which it could be predicted that there would be no relationship between anxiety and the attainment in speaking performance in English of the adolescent and adult learners. Also, the researcher predicted in the alternate hypothesis that there would appear a positive or negative impact of anxiety on adolescent and adult students' attainments in speaking performance.

\section{PARTICIPANTS}

Thirty learners divided into two groups participated in the study. The first group comprised of fifteen adults aged 30-40. The second group was formed of fifteen adolescents at the age of 17. Difference in gender was not of any concern. Nevertheless, the author of the study attempted to eliminate the conditions in which only males or females were engaged in the research. The participants firstly filled in the anxiety questionnaires, and then presented the speeches on the topics which had been discussed in previous lessons. This enabled to conduct the study reliably.

\section{MATERIALS}

Regarding materials applied in the study, the researcher administered: the anxiety questionnaire for the subjects comprising of twelve questions adapted from Horowitz \& Cope's Foreign Language Classroom Anxiety Scale, thirty sheets of paper with the speech topics for the subjects to draw and evaluation sheets for the teacher to complete.

\section{PROCEDURE}

The research was of quantitative type as this type of a study helped the researcher to focus more on the outcome of anxiety in foreign language learning, rather than the process of learning. The first part of the research comprised the students' filling in the anxiety questionnaire which had been previously adapted by the researcher from Horowitz \& Cope's Foreign Language Classroom Anxiety Scale (Horowitz et al., 1986). The second part of the research was devoted to evaluation of the subjects' speech samples. The learners, both adolescents and adults, performed three minute speeches on the selected topic. Then, the teacher evaluated their speech samples on six-point Likert scale by filling in the evaluation sheets. Finally, the researcher correlated computationally the data obtained from anxiety tests and the data from the evaluation of the subjects' speech samples. 


\section{DATA ANALYSIS}

After the research had been conducted, the results from the anxiety questionnaires along with the results from the evaluation sheets were correlated in order to examine whether there was any interdependence between anxiety of adult and adolescent students and their achievements in speaking performance.

Discussing the data obtained in the course of research, firstly the author of the study analysed the anxiety questionnaires. The researcher calculated all the categories of responses which fifteen adolescent and fifteen adult subjects had provided: that is the number of strongly agree, agree, neither agree nor disagree, disagree and strongly disagree.

The table below shows the results from adolescent subjects' responses in the anxiety questionnaire. As presented below, it can be concluded that the highest number of responses in the anxiety questionnaire was that of disagree. Therefore, it can be inferred that the adolescent subjects who participated in the study were rather determined providing their opinions on foreign language anxiety. Also, it can be noticed that the lowest number of responses was that of strongly agree which means that some adolescent subjects were aware of their low foreign language anxiety level.

Table 1. The list of the adolescent subjects' responses in anxiety questionnaire

\begin{tabular}{cccccc}
\hline $\begin{array}{l}\text { Questions from } \\
\text { the anxiety } \\
\text { questionnaire }\end{array}$ & $\begin{array}{l}\text { Strongly } \\
\text { agree }\end{array}$ & Agree & $\begin{array}{l}\text { Neither } \\
\text { agree, nor } \\
\text { disagree }\end{array}$ & Disagree & $\begin{array}{l}\text { Strongly } \\
\text { disagree }\end{array}$ \\
\hline 1. & 0 & 6 & 3 & 4 & 2 \\
\hline 2. & 0 & 3 & 0 & 9 & 3 \\
\hline 3. & 1 & 0 & 1 & 12 & 1 \\
\hline 4. & 1 & 4 & 2 & 8 & 0 \\
\hline 5. & 3 & 3 & 1 & 6 & 2 \\
\hline 6. & 2 & 4 & 0 & 9 & 0 \\
\hline 7. & 0 & 1 & 4 & 10 & 0 \\
\hline 8. & 2 & 3 & 0 & 8 & 2 \\
\hline 9. & 3 & 1 & 4 & 6 & 1 \\
\hline 10. & 2 & 3 & 1 & 8 & 6 \\
\hline 11. & 0 & 2 & 2 & 5 & 1 \\
\hline 12. & 0 & 2 & 2 & 10 & \\
\hline & & & & & 1 \\
\hline
\end{tabular}

Let us now concentrate on adults' responses. From the below table it can be inferred that the number of adults' responses of disagree was the highest, just like in the case of adolescents. Moreover, the number of responses strongly agree was the smallest also among adult students. On the other hand, it can be noticed that 95 of adolescent subjects' responses were disagree and only 65 of adult subjects' responses were disagree. It means that adults still remain more anxious than adolescents. 
Journal of Education Culture and Society No. 2_2018

Table 2. The list of the adult subjects' responses in anxiety questionnaire

\begin{tabular}{ccccc}
\hline Strongly agree & Agree & $\begin{array}{c}\text { Neither agree, } \\
\text { nor disagree }\end{array}$ & $\begin{array}{c}\text { Disagree } \\
\text { Strongly } \\
\text { disagree }\end{array}$ \\
\hline 5 & 2 & 6 & 1 & 1 \\
2 & 2 & 4 & 4 & 3 \\
1 & 4 & 4 & 4 & 2 \\
3 & 0 & 4 & 7 & 1 \\
1 & 4 & 3 & 4 & 2 \\
0 & 2 & 4 & 7 & 2 \\
0 & 3 & 3 & 5 & 4 \\
0 & 6 & 0 & 7 & 2 \\
0 & 4 & 6 & 3 & 2 \\
0 & 4 & 2 & 7 & 2 \\
1 & 1 & 3 & 6 & 3 \\
0 & 1 & 1 & 10 & \\
\hline
\end{tabular}

What was of greater importance for the researcher of this study was the estimation of the adolescent and adult subjects' anxiety. In order to do that, the author of the study calculated the number of disagree responses for individual adolescent and adult subjects. The researcher did not analyse strongly disagree responses as the number of strongly disagree responses would be too low to reach a reasonable conclusion.

Owing to the fact, that the anxiety test consisted of twelve questions, the researcher formed a scale according to which assigning the level of language anxiety to each of the subjects was possible. Students with nine to twelve of disagree responses were described as having low language anxiety (L). Medium anxiety was ascribed to the subjects with five to eight of disagree responses $(\mathrm{M})$ and regarding high language anxiety, it was ascribed to the adolescent and adult subjects with one to four of disagree response (H). Moreover, the numbers were assigned to the levels of language anxiety: 3 for low language anxiety, 2 for medium language anxiety and 1 for high language anxiety.

The table 3 shows the level of anxiety among adolescent subjects. As it has been revealed, the majority of ado-

Table 3. The results from language anxiety questionnaire describing the level of language anxiety in adult students

\begin{tabular}{ccc}
\hline $\begin{array}{c}\text { Adolescent } \\
\text { subjects }\end{array}$ & $\begin{array}{l}\text { Number of disagree } \\
\text { responses }\end{array}$ & $\begin{array}{l}\text { Anxiety } \\
\text { level }\end{array}$ \\
\hline 1. & 4 & $\mathrm{H} 1$ \\
2. & 1 & $\mathrm{H} 1$ \\
3. & 1 & $\mathrm{H} 1$ \\
4. & 3 & $\mathrm{H} 1$ \\
5. & 6 & $\mathrm{M} 2$ \\
6. & 9 & $\mathrm{~L} 3$ \\
7. & 11 & $\mathrm{~L} 3$ \\
8. & 8 & $\mathrm{M} 2$ \\
9. & 7 & $\mathrm{M} 2$ \\
10. & 8 & $\mathrm{M} 2$ \\
11. & 7 & $\mathrm{M} 2$ \\
12. & 7 & $\mathrm{M} 2$ \\
13. & 5 & $\mathrm{M} 2$ \\
14. & 4 & $\mathrm{H} 1$ \\
15. & 7 & $\mathrm{M} 2$ \\
\hline
\end{tabular}


lescent students possessed medium level of anxiety, which was not surprising. The number of adolescent students with high anxiety was also considerable. On the other hand, only two adolescent subjects received the status of being low anxious.

The table below shows the level of language anxiety among adult subjects from which can be concluded that in the majority of adult students' high level of anxiety was noticed. The number of students with medium anxiety was also substantial. However, only two adult subjects displayed low anxiety.

The analysis of the data revealed that the standard deviation, that is the spread of scores from anxiety questionnaire results for the adolescent students was 2.85 which meant that adolescent group was rather homogeneous. It shows that the scores obtained in the anxiety questionnaire were fairly similar to the mean of these scores. The standard deviation for adult students amounted 3.11 . It illustrates that the group of adult students was also rather

Table 4. The results from language anxiety questionnaire describing the level of language anxiety in the adult students

\begin{tabular}{ccc}
\hline $\begin{array}{c}\text { Adolescent } \\
\text { subjects }\end{array}$ & $\begin{array}{l}\text { Number of } \\
\text { disagree responses }\end{array}$ & Anxiety level \\
\hline 1. & 4 & L3 \\
2. & 1 & M2 \\
3. & 1 & H1 \\
4. & 3 & L3 \\
5. & 6 & M2 \\
6. & 9 & M2 \\
7. & 11 & H1 \\
8. & 8 & H1 \\
9. & 7 & H1 \\
10. & 8 & H1 \\
11. & 7 & H1 \\
12. & 7 & H1 \\
13. & 5 & H1 \\
14. & 4 & M2 \\
15. & 7 & M2 \\
\hline
\end{tabular}

Table 5. Descriptive statistics for the results obtained from adolescent and adult subjects' anxiety questionnaires

\begin{tabular}{lc}
\hline Statistics & Value \\
\hline Standard deviation-adolescent subjects & 2.85 \\
Standard deviation-adult subjects & 3.11 \\
\hline
\end{tabular}
homogenous regarding their anxiety. The standard deviation was calculated from the points obtained in the anxiety test, not from the numbers describing the level of anxiety assigned to them.

Following the procedure, the researcher gathered the data from the speech samples evaluated by the English teacher with the division into four categories: on topic/off topic, vocabulary, grammar and fluency. To assess the subjects' speeches, the researcher developed 6 points Likert's scale where 6 refers to excellent and 1 means very poor.

Firstly, the researcher calculated the mode and the mean rating of individual adolescent subject's speech sample (see Table 6). It can be noticed that the mode of the mean rating for fifteen adolescent subjects who participated in the study was 5 . It means that the most frequent score in the adolescent subject 
speech samples was 5 . It was also estimated that the mean rating for fifteen subjects was 4.96. When analysing the Table 6 , keeping in mind the fact that adolescent subjects delivered speeches without any preparation, it can be noticed that students performed very well. The researcher also calculated standard deviation from the scores obtained from adolescent students' evaluation sheets. It amounted 0.80, which clearly indicates that adolescent subjects are homogenous regarding their speaking attainments.

From the Table 7, it can be concluded that the mode rating for fifteen adult subjects who took part in the study was 5, so the most frequent score for adolescent students' speeches was 5. It was also estimated that the mean rating for thirty subjects as far as the evaluation of the adults' speech samples was concerned was 4.66. Adults also gave speeches without any preparation beforehand and they did really well. Finally, the author of the study calculated standard deviation from adult students' speech samples. It amounted 0.80 which clearly indicates that adult students form homogenous group concerning speaking achievements.

Description and presentation of the results led to the core of the study, primarily the accounts of anxiety questionnaire results and mean ratings for adolescent and adults' speeches separately, which is essential for further calculation of correlation between two variables. The results from adult subjects' (Table 8) and adolescent subjects' (Table 9) measurements are
Table 6. Descriptive statistics for the results obtained from adolescents' evaluation sheet

\begin{tabular}{lc}
\hline Statistics & Value \\
\hline Mode & 5 \\
Mean & 4.96 \\
Standard deviation & 0.70 \\
\hline
\end{tabular}

Table 7. Descriptive statistics for the results obtained from adults' evaluation sheet

\begin{tabular}{lc}
\hline Statistics & Value \\
\hline Mode & 5 \\
Mean & 4.66 \\
Standard deviation & 0.80 \\
\hline
\end{tabular}

Table 8 . The results from anxiety questionnaire and mean rating for the adolescent subjects

\begin{tabular}{ccc}
\hline $\begin{array}{l}\text { Adolescent } \\
\text { subjects }\end{array}$ & $\begin{array}{l}\text { Anxiety } \\
\text { questionnaire }\end{array}$ & $\begin{array}{l}\text { Mean rating } \\
\text { from the speech } \\
\text { rating }\end{array}$ \\
\hline 1. & 1 & 5 \\
2. & 1 & 6 \\
3. & 1 & 4.5 \\
4. & 1 & 5 \\
5. & 2 & 5.5 \\
6. & 3 & 6 \\
7. & 3 & 4 \\
8. & 2 & 5 \\
9. & 2 & 4 \\
10. & 2 & 4.5 \\
11. & 2 & 5 \\
12. & 2 & 5 \\
13. & 2 & 6 \\
14. & 1 & 4 \\
15. & 2 & 5 \\
\hline
\end{tabular}


displayed below.

In order to show the relationship between two variables, anxiety and speaking performance of adolescent and adult subjects, it is relevant to estimate the Pearson Moment Product Correlation Coefficient frequently illustrated as $r$. The value $r$ may be illustrated as $-1^{2} r^{3}$ +1 . The signs - and + illustrate positive and negative linear correlations. To understand the results of the Pearson Moment Product Correlation, it is vital to be aware of the fact that when $r$ value is close to +1 , it means that there is a positive linear correlation between the variables. When $r$ amounts exactly +1 , it illustrates a perfect match. The same rule can be applied to negative correlation but it concerns the number -1 . Lastly, when $r$ is close to 0 , it signifies none or a non significant correlation.

The correlation between anxiety of the adolescent subjects and their attainments in foreign language speaking revealed that there was no significant correlation between adolescent subjects' anxiety and their attainments in a second language as $r$ amounted 0.06. Adolescent subjects' medium anxiety did not affect their speaking performance. It means that the highly anxious person does not necessarily obtain worse scores in speaking performance and vice versa.

Regarding the adult subjects, there was only a weak positive correlation between the subjects' anxiety and their speaking performance with $r$ amounting -0.24 . The adult subjects' medium anxiety did not considerably affect their speaking performance.

\section{DISCUSSION}

The results of the study reveal that anxiety has no impact on students' speaking performance in the foreign language. The null hypothesis has been supported and the alternate hypothesis has been rejected. Nevertheless, some limitations of the study should be taken into account. Firstly, the number of the subjects could not have been sufficient to present entirely reliable data. There- 
fore, taking into consideration other research, the following study cannot be conclusive. There are other studies in literature which show the interdependence between anxiety and foreign language learning. Kondo \& Ying (2004) claim that anxiety is more likely to occur in speaking situations. Other research into language anxiety also reveals that anxiety affects foreign language performance (Aida, 1994).

It should be acknowledged that anxiety is only one of affective factors related to students' personality. However, one may argue that the other affective factors such as motivation, self-esteem or inhibition also play an important role in foreign language speaking. Thus, it would be relevant to conduct more researches not only on anxiety in second language learning but on other affective factors as well. As far as the following study is concerned, complementary study on larger samples of subjects should be conducted to reach more reliable conclusions.

\section{REFERENCES:}

1. Aida,Y. (1994). Examination on Horowitz, Horowitz and Cope's construct of Foreign Language Anxiety: The case of Students of Japanese. Modern Language Journal, 78, 155-168.

2. Brown, H. D. (2001). Teaching by Principles. White Plains, NY: Longman.

3. Cacciopo, J. (1994). Attitude Change. Encyclopaedia of Human Behaviour, Vol. I. Ohio: The Ohio State University.

4. Daly, J. A. (1991). Understanding Communication Apprehension: An Introduction to Language Educators. In: E. Horiwitz, \& D. Young (Eds). Language Anxiety: From Theory and Research to Classroom Implications (pp. 3-13). Engelwood Cliffs, N. J.: Prentice Hall.

5. Gierl, M., \& Rogers, T. (1996). A Confirmatory Factor Analysis of the Test Anxiety Inventory Using Canadian High School Students. Educational and Psychological Measurement, 56, 315-325.

6. Harleston, B.W. (1962). Test Anxiety and Performance in Problem Solving Situations. Journal of Personality, 30, 557-573.

7. Harmer, J. (2001). The Practice of English Language Teaching. Essex, England: Longman.

8. Hines, A. R., \& Paulson, S. E. (2006). Parents' and Teachers' Perception od Adolescent Storm and Stress. Relations with Parenting and Teaching Styles. Adolescence, 41, 597-614.

9. Horowitz, E. K. (1986). Preliminary Evidence for the Reliability and Validity of a Foreign Language Anxiety Scale. TESOL Quarterly, 20(3), 127-159.

10. Horowitz, E. K., Horowitz, M. B., \& Cope, J. (1986). Foreign Language Classroom anxiety. The Modern Language Journal, 70 (2), 125-132.

11. Kitano, K. (2001). Anxiety in the College Japanese Language Classroom. The Modern Language Journal, 8 (4), 549-566.

12. Komorowska, H. (2005). Metodyka nauczania jezzków obcych [Methodology of teaching foreign languages]. Warszawa: Fraszka Edukacyjna.

13. Kondo, D. S., \& Ying-Ling, Y. (2004). Strategies for Coping with Language Anxiety: The case of Students of English in Japan, ELT Journal, 58(3), 258-265.

14. Kostyuk, N., Meghanathan, N., \& Isokpehi, R. D. (2010). Biometric Evaluation of Anxiety in Learning English as a Second Language. International Journal of Computer Science and Network Security, 10 (1), 220-229.

15. Krashen, S. D. (1987). Principles and Practice in Second Language Acquisition. Englewood Cliffs, N. J.: Prentice-Hall International.

16. Latif, A. (2015). A Study on English Language Anxiety among Adult Learners in Universiti Teknologi Malaysia (UTM). Procedia-Social and Behavioral Sciences, 2008, 223-232.

17. Lightbown, P. M., \& Spada, N. (2006). How Languages are Learned. Oxford: Oxford University Press. 
18. McCroskey, J. C. (1987). Willingness to Communicate. In: J.C. McCroskey, \& J. A. Daly (Eds.). Personality and Interpersonal Communication (pp. 129-156). Thousand Oaks, Ca: Sage.

19. Novy, D. M., \& Nelson, D.V. (1995). Psychometric Comparability of the English-and SpanishLanguage Versions of the State-Trait Anxiety Inventory. Hispanic Journal of Behavioral Sciences, 17(2), 209-224.

20. Piechurska-Kuciel, E. (2008). Language Anxiety in Secondary Grammar School Students. Opole: Wydawnictwo Uniwersytetu Opolskiego.

21. Shastri, P. D. (2010). Communicative Approach to the Teaching of English as a Second Language Learning, 1, 153-161.

22. Spielberger, C. D. (1966). Anxiety and Behavior. New York: Academic Press.

23. Spielberger, C. D. (1972). Anxiety. New York: Academic Press.

24. Zohar, D. (1998). An Additive Model of Test Anxiety: Role of Exam Specific Expectations. Journal of Educational Psychology, 90 (2), 330-340. 